\title{
PACÍFICOS ACTORES, ÁVIDOS ESPECTADORES. \\ EL MERCURIO DE VALPARAÍSO Y LA COBERTURA DE LA Guerra del Paraguay
}

(1864-1870)

\section{PEACEFUL ACTORS, EAGER SPECTATORS. EL MERCURIO OF VALPARAISO AND THE COVERAGE OF THE PARAGUAYAN WAR (1864-1870)}

Nicolás Arenas ${ }^{1}$

Enviado: $27 / 07 / 2020$

Aceptado: 22/11/2020

Resumen: Este artículo examina las características y mutaciones de la línea editorial de El Mercurio de Valparaíso respecto a la Guerra del Paraguay (1864-1870). Pretende en su análisis colocar el foco en tres aspectos centrales que orientaron el discurso programático del periódico en relación con el conflicto trasandino: 1) la crítica evaluación de la gestión diplomática chilena en el Río de la Plata; 2) una intensa batalla dialéctica con un sector de la prensa de Buenos Aires y 3) la progresiva creación de un relato favorable a la causa paraguaya. A partir de esta aproximación, el estudio revela no solo la posición de un medio de comunicación de amplio alcance en el panorama publicitario local e internacional, sino también su comprensión sobre el rol de la

UANDES/Universidad de Los Andes - Chile.

Correo de contacto: narenas@miuandes.cl 
prensa como espacio de construcción de la opinión pública alrededor de los enfrentamientos armados en América durante la década de 1860.

Palabras clave: Prensa; Chile; El Mercurio; Guerra del Paraguay.

Abstract: This article examines the characteristics and mutations of the editorial line of El Mercurio of Valparaíso regarding the Paraguayan War (1864-1870). In its analysis, it seeks to focus on three central aspects that guided the newspaper's programmatic discourse in relation to the trans-Andean conflict: 1) the critical evaluation of Chilean diplomatic management in the Río de la Plata; 2) an intense dialectic battle with a sector of the press in Buenos Aires and 3) the progressive creation of a favorable account of the Paraguayan cause. From this approach, the study reveals not only the position of a media with a wide reach in the local and international advertising scene, but also its understanding the role of the press as a space for building public opinion around the armed confrontations in the Americas during the 1860s.

Keywords: Press; Chile; El Mercurio; Paraguayan War. 


\section{Introducción}

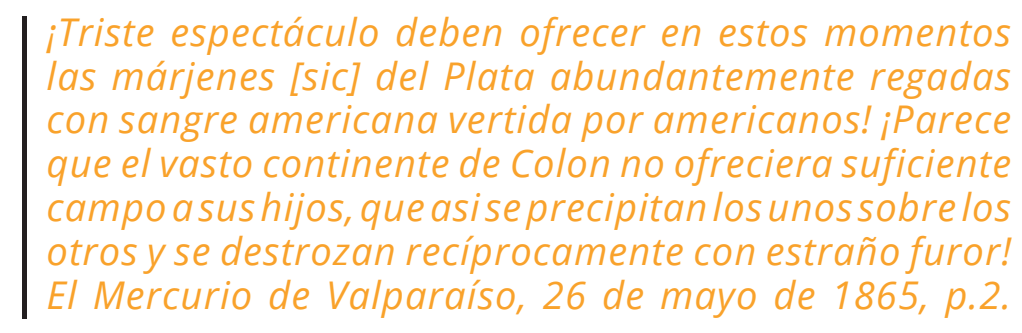

Las palabras del intelectual chileno Joaquín Godoy, que cerraban una de las editoriales de El Mercurio de Valparaíso, revelan la atención y preocupación que despertó en Chile el conflicto que, por ese entonces, enfrentaba al Paraguay con los poderes aliados de Argentina, Uruguay y Brasil (1864-1870). La prensa chilena, y en particular el periódico de la ciudad portuaria, siguió con interés los avances y retrocesos de la contienda bélica, brindó a sus lectores continuas crónicas de sucesos y valoraciones sobre el accionar de cada una de las naciones participantes -y sobre muchos de sus protagonistas-, así como acerca de la actitud que debían asumir las autoridades nacionales en relación con aquellos eventos.

A partir de ello, este artículo pretende examinar las características del posicionamiento editorial del periódico de Valparaíso respecto a la Guerra del Paraguay y advertir las mutaciones que sufrió su discurso a lo largo de la contienda. Mediante un estudio que relaciona los contextos de edición y producción del diario (Louis, 2014) con una exégesis de su articulado, se analizan tres líneas programáticas centrales de su postura editorial: 1) la crítica evaluación de la gestión diplomática chilena en el Río de la Plata; 2) la disputa con un sector de la prensa de Buenos Aires (en particular con La Nación Arjentina) y 3) la imposición progresiva dentro del espacio publicitario chileno de un discurso en favor de la causa paraguaya. Al hacerlo se percibe el uso de las tribunas del diarismo como medio informativo, pero a la vez como herramienta discursiva, por lo que la aproximación pro- 
puesta interroga dicha postura del soporte en su perceptible relación con dos procesos sincrónicos que se imbrican en su relato y que permean muchas de las opiniones allí expuestas: por una parte, el conflicto que por ese entonces enfrentaba a las naciones del Pacífico (Chile, Perú y Ecuador) con España y, al mismo tiempo, el histórico diferendo argentino-chileno respecto a los límites patagónicos.

Las investigaciones que anteceden este artículo y que indagan sobre la posición de El Mercurio respecto a la Guerra del Paraguay (Lacoste, 1995-1996, 1997) efectúan un ineludible examen acerca del rol del periódico de Valparaíso como medio de circulación de las noticias sobre la guerra y tribuna para la consagración de una postura americanista, que buscaba imponerse en tensión y diálogo frente a los discursos patrióticos que articulaban el proceso de construcción nacional que marcó la segunda mitad del siglo XIX. No obstante, los trabajos de Lacoste se circunscriben a un período particular del conflicto (1866-1868) y enfocan su atención en ciertos personajes que blandieron argumentos que representaban a ambos discursos (José Victorino Lastarria, Domingo Faustino Sarmiento, Juan Bautista Alberdi, Bartolomé Mitre) y en algunos hitos que a nivel regional se conectan con el conflicto paraguayo (la disputa entre colorados y blancos en Uruguay o los levantamientos armados en las provincias de Cuyo).

En tal sentido, este texto dialoga con estos escritos previos, extiende el marco cronológico de análisis y explora respecto a la trascendencia del periódico como plataforma performativa mediatizadora (Paatz, 2001: p.3) y en el rol del publicista como agente capaz de incidir en la esfera pública y formar opinión, tanto a nivel local como trasnacional (Ossandón, 1998: p.10). Tal acción fue acometida con diversa intensidad por algunos trabajos previos que recorren la prensa de los países beligerantes (Baratta, 2012a, 2012b; Caballero y Ferreira, 2007; Doratioto y Monteoliva, 1993; Johansson, 2011, 2012a, 2012b, 2014, 2017; Johansson y Sujatovich, 2012; Johnson, 2006; Román, 2016; Silveira, 2009, 2014; Sujatovich, 2014; Valero, 2015; Whigham, 2012); pero aún no ha sido replicada 
en relación con los medios de comunicación impresa externos a la contienda ${ }^{2}$. En torno a estos soportes es necesario asumir un acercamiento que los interrogue, de forma simultánea, desde el punto de vista de la historia política y la historia de la prensa (Alonso, 2015: p.11), sin que se excluya su valor como herramienta cultural y social en el ámbito publicitario decimonónico y su rol protagónico dentro del mundo de la cultura escrita (Charle, 2004: pp.16-21).

\section{Escribir a orillas del Pacífico sobre un lejano conflicto}

La década de 1860 estuvo marcada en Chile, en términos políticos, por la lenta contracción del elemento conservador y la imposición progresiva de los sectores liberales que, aunque vencidos en la revolución de 1858-1859 contra las fuerzas del presidente Manuel Montt, lograron ganar espacio dentro de la nueva Administración de José Joaquín Pérez (1861-1871). Esta nueva época (Collier, 2005: p.307) estuvo acompasada por un notable crecimiento económico de la producción y exportación de productos mineros y agrícolas, elemento que junto a la estabilidad política y la defensa que el nuevo presidente accionó respecto a la prensa, repercutieron dentro del mundo publicitario nacional y apuntalaron su desarrollo ${ }^{3}$.

Durante esos años, Valparaíso se erigió como nodo intelectual y comercial que disputó la hegemonía del espacio publicitario chileno con la capital. Con una población de 74.731 habitantes según el censo de 1865 -en un total de habitantes del país que ascendía a 1.819.223-,

2 Puede señalarse como excepción el trabajo de Ricardo Scavone Yegros (2018), que profundiza en el estudio de las relaciones entre Paraguay y Colombia y dedica un apartado a examinar el posicionamiento de la prensa colombiana en relación con la Guerra del Paraguay.

3 El investigador Simon Collier afirma que la defensa de la libertad de prensa asumida por el presidente Pérez se observó desde su asunción, momento en que un polémico texto como el Cuadro histórico de la administración Montt -fruto de las plumas de José Victorino Lastarria, Diego Barros Arana, Marcial González y Domingo Santa María y publicitado bajo el sello de la imprenta de El Mercurio- no propició ningún tipo de castigo por parte de la justicia o el Poder Ejecutivo (Collier, 2005: p.308). 
la ciudad portuaria poseía 129 tipógrafos en toda la provincia (más 21 encuadernadores y 9 litógrafos), guarismo que casi equiparaba al de Santiago (137 tipógrafos), cuya población duplicaba a la del enclave porteño ${ }^{4}$ (168.553 habitantes) (Gobierno de Chile, 1865: pp.199-207). Asimismo, su posición como epicentro del tráfico marítimo en el país -el cual demostraba un progresivo incremento-, la convirtió en ámbito central del intercambio libresco y espacio propicio para el despliegue de la industria del impreso.

En este contexto, la Imprenta de El Mercurio, en manos de la familia española Tornero, se presentaba como la principal empresa de producción bibliográfica -en el más amplio sentido del término- de la ciudad portuaria. No obstante, cabe destacar que al iniciar la década de 1860 la firma comercial transitaba un periodo de recuperación luego de las aciagas circunstancias de la revolución de 1858-59, que implicaron el cierre de la imprenta por parte del Gobierno
(14 de diciembre de 1858 a 7 de marzo de 1859) y afectaron directamente su economía (Arenas Deleón, 2019: pp.71-72). Por lo mismo, y para revertir esta adversa situación financiera, los años subsiguientes observaron la creación de diversas estrategias para acaparar el gusto lector y así elevar las ventas y con ello las entradas para la supervivencia del negocio.

Dentro de este proyecto de recuperación del establecimiento impresor, el diario poseía una importancia primaria, pues era el soporte que sostenía financieramente el resto de la estructura publicitaria (libros, revistas, folletos), así como también el funcionamiento de las librerías en Valparaíso, Santiago, Copiapó, La Serena y San Felipe (Subercaseaux, 2000: pp.70-73) y la fábrica de papel "S. Tornero y Bravo", instalada en Limache (Salazar, 2009: p.642). Si bien desde su fundación en 1827 los avisos comerciales mantenían económicamente esta creciente estructura, durante este periodo las crónicas de sucesos nacionales e internacionales fueron

4 A lo largo del artículo se utiliza la voz "porteño" como gentilicio de las personas originarias de Valparaíso, mientras que se emplea el término "bonaerense" para los nacidos en Buenos Aires. 
ganando espacio dentro de las páginas del formato y desplazando el contenido publicitario.

Es difícil establecer el momento exacto de esta transición, pero es probable que el conflicto en el Pacífico (18641866) despertara en el público local especial interés y provocara la sucesión constante, desde 1864, de crónicas y editoriales centradas en la guerra. Igualmente, y en tanto plataforma performativa (Austin, 1962: p.293) de carácter político, el periódico sirvió a los publicistas porteños, durante esta coyuntura, para defender una postura sobre los hechos -en este caso la causa de los países americanos frente a España- ante la opinión pública. Para difundir esta posición fue de suma utilidad la extensa red de circulación del impreso construida durante más de tres décadas, tanto a nivel nacional (Ancud, Arauco, Cauquenes, Casablanca, Chillán, Chiloé, Colchagua, Combarbalá, Concepción, Constitución, Copiapó, Coquimbo, Curicó, Curacaví, Freirina, Hualqui, Huasco, Illapel, La Serena, Ligua, Limache, Linares, Llico, Los Ángeles, Maule, Melipilla, Molina, Nacimiento, Osorno,
Ovalle, Parra, Petorca, Puerto Montt, Putaendo, Quillota, Quirihue, Rancagua, Rengo, San Carlos, San Felipe, San Fernando, Santa Rosa, Santiago, Talca, Tomé, Valdivia, Vallenar) como internacional (Mendoza, Buenos Aires, Paraná, Rosario, Córdoba, San Juan, Montevideo, Rio de Janeiro, Cobija, Cochabamba, La Paz, Oruro, Sucre, Iquique, Arica, Tacna, Arequipa, Lima, Guayaquil, Panamá, Bogotá, Caracas, Costa Rica, México, San Francisco, Nueva York, La Habana, Liverpool, Londres, Edimburgo, París, Le Havre, Burdeos, Bruselas, Amberes, Madrid, Barcelona, Málaga, Sevilla, Hamburgo y Berlín). Este entramado de agencias y puntos de venta lo convirtieron en el periódico de mayor circulación transnacional durante la década de 1860 (Silva Castro, 1958: p.153) y el segundo a nivel local, solo por detrás de El Ferrocarril de Santiago.

La internacionalización del periódico también se vio auxiliada por el trasiego de vapores, los cuales conectaban la ciudad con las principales capitales a lo largo del continente y allende el Atlántico. Dicha conexión permitió, 
asimismo, estar al corriente de los principales acontecimientos que se desarrollaban fuera de fronteras y dar cuenta de ellos en las páginas del soporte, a través de una sección que se tituló "Crónica extranjera" y que contenía informaciones de corte político, económico o cultural del más diverso origen (periódicos locales o extranjeros, corresponsales, telegramas, etc.).

De tal forma, el flujo de noticias y el interés lector por la guerra provocaron que, hacia finales de 1864 y fruto de las hostilidades que comenzaban a manifestarse al otro lado de la Cordillera, las noticias del Atlántico acapararan buena parte de la sección de crónica internacional de El Mercurio. Así, en octubre de ese año se detecta la primera referencia a la tensión existente a orillas del Plata, en una columna que entregaba información referente al fracaso de la misión Saraiva y la invasión del Ejército imperial del Estado Oriental ${ }^{5}$. Igualmente, este primer artículo relataba la tensión en la relación paraguayo-brasileña y auguraba, en caso de no hallarse una pronta solución, el estallido de un enfrentamiento armado entre ambas naciones.

La expectativa en torno a posibles combates en el Atlántico se utilizó constantemente como artilugio para conservar e incentivar la avidez lectora. Para ello fue necesaria la publicación casi diaria de noticias, a pesar de que su flujo fue intermitente -por su dependencia directa del arribo de barcos a la rada de Valparaíso- y de que observaron una diferencia de entre dos y cuatro semanas entre la fecha de emisión y/o publicación en la margen atlántica y la irrupción en las páginas del periódico porteño. El trabajo de los responsables del soporte a través de una precisa y meditada administración de los contenidos existentes -práctica que implicaba fragmentaciones y omisiones- y la utilización de otras vías para su obtención -la ruta terrestre que unía al puerto con la capital del país-, sirvieron para subsanar aquellos inconvenientes y favorecer al público con continuas novedades.

Respecto al origen de los contenidos, un recorrido a través de los textos que completaron

5 El Mercurio, 27 de octubre de 1864, p.2. 
el espacio de noticias sobre el conflicto entre Paraguay y la Triple Alianza manifiesta la preeminencia de transcripciones de materiales (migraciones textuales) de periódicos de diversos orígenes: chilenos (EI Independiente, El Ferrocarril, La Patria), argentinos (La Nación Arjentina, El Pueblo, La Tribuna, El Nacional, The Standard, La República, La América, El Ferrocarril de Rosario, La Capital de Rosario, La Prensa de Rosario, El Comercio de Paraná, El Progreso de Corrientes, El Eco de Corrientes), brasileños (Jornal do Commercio), paraguayos (El Seminario de Avisos y Conocimientos Útiles), uruguayos (EI Siglo, La Reforma Pacífica, La Europa, La Tribuna, El Correo), peruanos (El Comercio) e incluso de materiales publicados en diarios y revistas europeas
(Gazette de France, Presse de France, Revue des Deux Mondes, La Época de Madrid). En segundo lugar, se percibe la presencia de distinta documentación que acompañaba (o no) esas notas extranjeras o locales (decretos, partes de guerra, proclamas, reglamentos, tratados, cartas, etc.), así como de breves notas elaboradas por diversos corresponsales del periódico en la región, especialmente en Mendoza, Rosario, Córdoba y Buenos Aires. Por último, las editoriales que ejecutaron los sucesivos responsables del formato (Florentino González, 1864-1865; Joaquín Godoy, 1865; Camilo Cobo, 1866 1869 y Manuel Blanco Cuartin, 1869-1884) completaron los contenidos que describieron y examinaron las características y el avance del conflicto.

\section{3. "Por una copa de más". Lastarria en la mira de la prensa}

La práctica periodística en Chile y el funcionamiento de la prensa en aquel país estaban regulados por la ley de imprenta de 1846. Esta reglamentación sometió a los medios de comunicación impresa al férreo control del Gobierno (Santa Cruz, 1988: p.21) y castigó duramente (con multas y penas de prisión y presidio) toda manifestación contra las autoridades locales o nacionales ${ }^{6}$. Asimismo, la adjudicación de

6 Según el historiador chileno Patricio Ibarra Cifuentes, "las situaciones causales de ser juzgadas y castigadas en todas las leyes de impren- 
la responsabilidad última a los impresores o editores respecto a lo expuesto en las publicaciones generó reparos en torno a lo que aparecía en las páginas de los periódicos y numerosas tensiones entre la familia Tornero y los distintos redactores del periódico, mucho más después del cierre de la imprenta a finales de la década anterior (Tornero, 1889: pp.65-66).

Sin embargo, la prensa logró eludir al menos parcialmente dicha legislación y esgrimió opiniones críticas sobre diversas figuras del gobierno de José Joaquín Pérez. En tal sentido, la campaña negativa que los medios de comunicación chilenos orquestaron alrededor de la misión de José Victorino Lastarria en el Río de la Plata (1865-1866) Ilama especialmente la atención, en tanto parte de la impugnación a sus acciones se vinculó a los sucesos que ocurrían en el Paraguay.
Desde su entrada en la capital argentina como Ministro Plenipotenciario y Enviado Extraordinario del Gobierno de Chile ante la Argentina, el Estado Oriental y el Imperio del Brasil, en enero de 1865 -en medio de la celebración de los funerales de las víctimas de Paysandú-, Lastarria despertó el interés de la opinión pública a ambos lados de la Cordillera de los Andes. Según el redactor de El Mercurio, el neogranadino Florentino González, la prensa local depositaba esperanzas en que el nuevo funcionario sumara al doble cometido de su misión (la negociación de los límites patagónicos y la obtención de ayuda para la guerra con España en el Pacífico) uno nuevo: facilitar la mediación de su Gobierno en el conflicto del Paraguay. Incluso, algunos medios de prensa de Buenos Aires anunciaban que el representante chileno "ya había sometido a los representantes de las naciones interesadas algunas proposiciones con este objeto"7.

ta chilenas del siglo XIX, pueden ser resumidas en cuatro conceptos básicos: blasfemo (Ofensivo de los preceptos de la religión del Estado, es decir, la Católica, Apostólica y Romana), inmoral (Vulneración de la moral y las buenas costumbres de la época), sedicioso (Atentatorio de la seguridad, integridad o las instituciones del Estado) e injurioso (Agravios o imputación de actos contra personas particulares o funcionarios públicos)" (Ibarra Cifuentes, 2014: p.300).

7 El Mercurio, 3 de marzo de 1865, p.2. 
Según examina Pablo Lacoste (1997: p.575), y tal como advierte la correspondencia intercambiada con el Ministro de Relaciones Exteriores de Pérez, Álvaro Covarrubias, Lastarria buscaba anteponer su afán americanista -claramente expuesto meses después en su obra La América (1865) - a los intereses chilenos, lo que le costó el intenso ataque de la prensa bonaerense (por su intromisión en asuntos internos de un país ajeno) y de los medios chilenos (debido a cierta debilidad en las negociaciones con el Gobierno de Mitre).

Así, durante los meses de febrero y marzo de 1865 , la acción de Lastarria comenzó a generar cierto recelo en la prensa de Buenos Aires, especialmente en las páginas de La Nación Arjentina, donde se inició una campaña contra Chile y su representante. Esta operación llamó la atención de Florentino González, quien afirmó que la intención de aquel medio de prensa era "agriar con un lenguaje destemplado y acre tanto como provocativo las cuestiones que se discuten entre la prensa de ambos países". Igualmente, descubrió que tras esta agresión corría el rumor de la formación de un ejército en Santiago con la finalidad de ocupar el territorio patagónico en nombre del Gobierno chileno ${ }^{8}$. Dicha práctica discursiva efectuada desde los espacios de la prensa afectó la acción del nuevo representante diplomático y relegó cualquier interés americano frente a la afirmación nacional y la reclamación de territorios en disputa.

Asimismo, la acción de los periódicos de Santiago y Valparaíso allanó en poco los movimientos de Lastarria. Según el diplomático, las constantes acusaciones a los gobiernos de Argentina y Brasil por su apoyo a Venancio Flores, enervó los ánimos en la capital argentina y generó la animadversión hacia los chilenos. De igual modo, la defensa del régimen de Francisco Solano López por parte de algunos diarios trasandinos -con El Independiente a la cabeza- tampoco facilitó las cosas para el enviado.

No obstante, el momento más álgido se vivió con posterioridad al $1^{\circ}$ de mayo de 1865, y estuvo relacionado con

8 El Mercurio, 24 de marzo de 1865, p.2. 
el accionar de Lastarria en un banquete oficiado en Buenos Aires por el presidente Mitre para celebrar la firma del Tratado de la Triple Alianza y su nombramiento como jefe de los ejércitos aliados. A dicho evento acudieron el representante brasileño Francisco Otaviano de Almeida, el Ministro de Relaciones Exteriores de Uruguay Carlos de Castro y una comitiva que superaba las cuarenta personas. El único asistente que no pertenecía a los tres estados signatarios del acuerdo era el enviado chileno, lo que generó suspicacias en la opinión pública respecto a las razones de su presencia.

Pero más que la asistencia de Lastarria al encuentro -la cual podía explicarse como un gesto de camaradería de su amigo
Mitre-, lo que más sorprendió e inquietó a la prensa chilena fue el discurso y el brindis que este realizó en aquella cena. Los responsables de El Mercurio suscribieron a dos editoriales de El Ferrocarril y El Independiente en que se condenaron las palabras del diplomático ${ }^{9}$. En ellos se subrayaba lo inoportuno de sus expresiones, pues exteriorizaban el apoyo a la causa aliada y al tratado a nombre del Gobierno chileno. El primero de los periódicos sostenía al respecto: "ignoramos las instrucciones que nuestro diplomático en el Plata tenga; pero nos permitimos dudar que esas instrucciones le ordenaran aplaudir las intervenciones y alentar para la guerra a ninguno de los pueblos cerca de cuyos gobiernos iba acreditado". El Independiente era aún más incisivo acerca del

9 El discurso pronunciado por Lastarria fue publicado en las páginas de El Mercurio y expresaba lo siguiente: “Las nobles palabras del Presidente de la Republica [Bartolomé Mitre] me hacen notar un hecho que está escrito con letras de sangre en la historia de América: ese hecho que nos muestra a los pabellones de las repúblicas del Plata y del Brasil, defendiendo y haciendo triunfar la causa de la civilización y de la democracia contra la barbarie. Yo hago votos, señores, por que ese hecho no se contradiga jamás, por que esos pabellones hagan triunfar siempre esa gran causa, si alguna vez la barbarie pone en ella una macha que la empañe.

${ }^{B}$ rindo, señores, por que el pueblo paraguayo recobre sus derechos a la sombra de esos pabellones, por que constituya un gobierno digno que represente dignamente a esta pléyade de repúblicas que en el firmamento de la civilización moderna señala a la humanidad su porvenir". "Boletín del día", El Mercurio, 14 de junio de 1865, p.2. 
accionar de Lastarria y sostenía que sus manifestaciones eran "una esplicita aprobación de la triple alianza y una condenacion contra la causa del Paraguay, y lo que es peor, contra su gobierno. $Y$ decimos que esto es peor, porque es ya, no solo aprobar la intervención, sino en cierto modo tomar parte en ella"10. De igual forma, los tres medios de prensa consideraron inoportuno que una decisión individual enemistara al país con el Gobierno de López, con quien Chile mantenía cordiales relaciones.

Sin embargo, la alocución de Lastarria no resultó fortuita o accidental. Así lo testimonia el discurso del diplomático chileno en la recepción que Venancio Flores le prodigó en su arribo a Montevideo, el cual demuestra una línea de pensamiento respecto a su posicionamiento ante la guerra. En dicho acto celebró nuevamente el avance de los ejércitos aliados sobre el Paraguay en aras de la libertad y la independencia y argumentó que:

\section{Las guerras americanas no serán justificadas a}

los ojos de la historia, sino en tanto que como sucesos lójicos de nues. tro trabajo de reorganización, y de rejeneracion [sic], ellas tiendan a hacer triunfary a consolidar los intereses lejitimos de la sociedad y los principios sobre [los] que reposa nuestro porvenir: cualquiera otro interes egoista en nuestras contiendas merecerá la execración de las jeneraciones presentes y de las futuras ${ }^{11}$.

En medio del contexto regional, las palabras expuestas tanto en el brindis como en la recepción uruguaya podrían haber significado una estrategia para quebrar la neutralidad de los Gobiernos de Argentina y Uruguay respecto al conflicto del Pacífico y obtener algún tipo de auxilio; sin embargo, no dejaban de llamar la atención de la prensa chilena y argentina. A pesar de este intento de atraer el favor de las autoridades rioplatenses, la percepción del diplomático revelaba la intransigencia irrestricta de uruguayos y argentinos

10 El Mercurio, 6 de junio de 1865, p.2.

11 "El ministro chileno en Montevideo", El Mercurio, 13 de julio de 1865, p.3. 
acerca de apoyar las preten- de 1866, la prensa de la capital siones chilenas y declarar la argentina solo expuso una conguerra a España. Incluso ante dena puntual al acto ${ }^{12}$, pero no el impactante bombardeo de fijó un posicionamiento firme Valparaíso, a finales de marzo en favor de la causa americana.

\begin{abstract}
Paralelamente, su discurso tampoco encontró eco en el Gobierno y la prensa uruguaya, con quienes se enfrascó en el mentado problema de las presas, el cual El Mercurio siguió casi diariamente. Lastarria, como parte de su misión diplomática, tenía por objetivo solicitar ante el Gobierno oriental la habilitación para "las operaciones de corsarios chilenos contra los barcos mercantes españoles" (Lacoste, 1995-1996: p.132) y facilitar la posibilidad de arribo al puerto de Montevideo para la venta de las presas. No obstante, según consignaba el redactor de El Mercurio Camilo Cobo, la debilidad del diplomático había consentido que las autoridades uruguayas se mostraran favorables a la acción española en el Atlántico, lo que en una guerra dispar favorecía de manera clara a los europeos. Por tanto, desde las páginas del periódico porteño se consideraba imperioso que el enviado tomara una enérgica acción, pues "no es justo que permanezcamos amigos con un Gobierno cuya conducta es la enemistad mas abierta
\end{abstract}

12 En abril de 1866, los principales responsables de La Tribuna (Mariano Varela), El Nacional (Carlos D'Amico y Eduardo Wilde), La Nación Argentina (Salustiano Zavalla y José María Gutiérrez), El Pueblo (Isaac de Tezanos), La América (Agustín de Vedia), El Correo del Domingo (José María Cantilo), The Standard (periódico británico publicado en Buenos Aires bajo la dirección de los hermanos Michael y Edward Mulhall), Le Courrier de la Plata (Ch. Berry), El Mosquito (Luciano Choquet), La Revista de Buenos Aires (Vicente Quesada y Miguel Navarro Viola) y el director del periódico alemán (Enrique Curth) rubricaron la proclama que se solidarizaba con la ciudad portuaria del Pacífico luego del embate de las fuerzas españolas (Quesada, 1866: pp.321 y ss.). Ver también Carta de Mariano Varela e Isaac de Tezanos a los redactores de La Revista de Buenos Aires, Buenos Aires, 28 de abril de 1866. Archivo de la Academia Nacional de la Historia Argentina, Fondo Miguel Navarro Viola, Caja 2, fol. 36 . 


\section{contra Chile, aunque ella se encuentra hipócrita-
mente con la capa de la simpatía por nuestra causa"13.}

Empero, las autoridades orientales se adelantaron a la jugada propuesta en los espacios periodísticos trasandinos al quitar el exequatur concedido al diplomático (21 de diciembre de 1865) y entregarle el pasaporte para su salida de la capital uruguaya. El Mercurio, contrario a la determinación del Uruguay, protestó con vehemencia, publicó la correspondencia intercambiada entre los funcionarios uruguayos y el enviado chileno ${ }^{14}$ y reprodujo artículos de medios de prensa como La Tribuna de Buenos Aires que condenaron el accionar de la Administración de Flores ${ }^{15}$.

A partir de ello, muchas de las noticias surgidas en Valparaíso y Santiago tras la ruptura de relaciones, que acusaban al Gobierno uruguayo de ejercer una conducta pro española y enemiga de la causa americana, llegaron al puerto de Montevideo y fueron transcritas e impug- nadas por el periódico local La Tribuna. De tal modo, la reflexión del diario oriental -con el apoyo de medios importantes de la prensa bonaerense como La Nación y El Nacional- se focalizó en la defensa del carácter americanista del Uruguay y en explicar las razones de cada una las decisiones asumidas por su Gobierno. En primer término, consideró exageradas las opiniones de la prensa chilena respecto al accionar del Uruguay en torno a la "cuestión Lastarria". Además, justificó que la posición sobre el tema de las presas era lógica en una coyuntura de conflicto, cuando no era conveniente sumar a la guerra con el Paraguay un nuevo frente, y afirmó que la prensa chilena no podía ser crítica de estos actos, pues “hacían ardientes votos por el triunfo de las ideas democráticas representadas por López en la lucha que sostiene contra la triple alianza"16.

\footnotetext{
13 "El Uruguai", El Mercurio, 22 de enero de 1866, p.3.

14 Suplemento del Mercurio, 4 de febrero de 1866, p.2 y El Mercurio, 5 de febrero 1866, p.2.

15 El Mercurio, 23 de enero de 1866, p.2.
16 "La prensa chilena (La Tribuna de Montevideo)", El Mercurio, 20 de marzo de 1866, p.2.


Aunque la misión se cerró sin mayores sobresaltos en octubre de 1866, su análisis deja en evidencia, en primer término, el poder de los medios de comunicación como articuladores de la opinión pública local -al provocar, por ejemplo, una profunda y progresiva animadversión entre chilenos $y$ argentinos- $y$, en segundo lugar, demuestra la forma en la que accionaron estos sopor- tes como espacio para la crítica, el diálogo y la discusión (Rubilar, 2015: p.87) respecto a diversos tópicos relacionados con el conflicto armado en ambos extremos del continente. Igualmente, el examen del discurso esgrimido por Lastarria muestra la pulsión entre un discurso americanista y la defensa de los intereses nacionales dentro del espacio regional.

\section{Un duelo de palabras a través de la Cordillera}

Las tensiones que chilenos y argentinos experimentaron a causa del contexto de guerra también se tradujeron en el campo periodístico. Durante la duración de ambos conflictos, El Mercurio -y con él buena parte de la prensa chilena- experimentó una intensa disputa dialéctica con los medios bonaerenses, en particular con La Nación Arjentina (1862-1869), diario de prestigio en la capital argentina, cercano al presidente Mitre (Baratta, 2012a: p.88) y bajo la dirección del reconocido político José María Gutiérrez. Al respecto, ciertas aproximaciones han catalogado este intercambio como la querella entre un relato de defensa del americanismo (El Mercurio) frente a un discurso de corte eminentemente nacionalista (La Nación Arjentina) que "menospreciaba esas tendencias para subordinarlas a la pareja de opuestos civilización y barbarie" (Lacoste, 1997: p.589). No obstante, si bien en el caso chileno la inclusión de artículos de intelectuales como Juan Bautista Alberdi o José Victorino Lastarria puede abonar dicha hipótesis, también las páginas de El Mercurio fueron tribuna para la defensa del nacionalismo chileno frente a la opinión pública argentina.

Las primeras manifestaciones en torno a la distancia entre ambos medios de prensa fueron expuestas por Florentino González, en tanto responsable 
de los contenidos del formato de Valparaíso, a inicios de 1865. Según el redactor de El Mercurio, el órgano periodístico bonaerense había establecido desde hacía varios meses una intensa campaña de desprestigio contra Chile, fundada en una valoración heterodoxa que efectuó el periódico porteño respecto a la invasión del territorio oriental por parte del ejército imperial. La prensa chilena objetaba, desde el año anterior, la pasividad del Gobierno de Mitre frente a lo que consideró un ataque directo al poder legalmente constituido en Uruguay. Aunque González aclaró que "la prensa de Chile no ha[bía] condenado la política del gobierno arjentino, sino que ha[bía] tratado de esclarecer lo que había en ella de oscuro y misterioso"17, acusó directamente a la opinión pública y a las autoridades argentinas de proteger los intereses ilegítimos de Venancio Flores y del Imperio en la cuestión uruguaya.

Aquella acción de desprestigio orquestada por La Nación Arjentina también imputó al diario de Valparaíso la falta de independencia respecto a grupos políticos a nivel local y nacional -situación que, aunque negada por La Nación, también vivían los formatos argentinos-, quienes incidían, según el medio bonaerense, en los contenidos y opiniones que se presentaban en El Mercurio. Esta subordinación de la prensa a intereses de partido era, en términos del redactor del periódico argentino, fruto de una prensa atrasada, con falta de libertad y autonomía; lo que conspiraba para la creación de tribunas periodísticas "ligada[s] al pueblo, [que] vive[n] del pueblo y para el pueblo, le enseña[n], le ilustra[n] y le dirije[n] en sus movimientos". Así, la cuestión se planteaba en términos dicotómicos respecto a los espacios periodísticos a ambos lados del cordón cordillerano: atraso-modernidad, oscurantismo-regeneración, barbarie-civilización, colocando como línea rectora del discurso las "rivalidades de aldea y de campanario", más que la reflexión sobre el crítico escenario americano. Ante ello, la respuesta del redactor colombiano de El Mercurio fue tajante: todo lo expuesto La Nación Arjentina tendía a "desnaturalizar los hechos y las opiniones que no son de

17 El Mercurio, 24 de marzo de 1865, p.2. 
su simpatía", pues el interés central del periódico chileno no era otro que la defensa de la unidad americana ${ }^{18}$.

Otro hito en la discusión se halla en un artículo de la "crónica extranjera" de El Mercurio, publicado el 14 de noviembre de 1865, en que se refleja la escalada de esta conflictividad. En dicha entrega del periódico apareció una columna bajo el título "Prensa arjentina. A La Nación Arjentina", en que su autor-oculto tras el seudónimo "Un chileno"- comentó ciertas afirmaciones expuestas en el soporte argentino acerca del conflicto entre Chile y España. Según este chileno, el periódico argentino en el tratamiento de aquel enfrentamiento no había defendido con convicción a la nación americana, sino que, por el contrario, había realizado una evaluación donde condenaba el accionar de ambos contendientes $^{19}$ con la finalidad de evitar un ataque directo a España. Esta posición discursiva se explicaba por dos razones: por un lado, en el enorme ascendiente que la comunidad española de Bue- nos Aires observaba dentro del mundo periodístico local -incluso con la promoción de sus propios medios de prensa en la ciudad y la región (la Razón Española, el Imparcial, el Español y la Europa de Montevideo) - y, por otro lado, por la postura crítica de la prensa chilena relativa al avance sobre Paraguay. Ante ello, la insistencia por un pronunciamiento favorable de la prensa y el auxilio del Gobierno ante la causa chilena fue recurrente; especialmente en momentos en que se producía el incidente con la nave española Covadonga (26 de noviembre de 1865), apresada por las armas chilenas frente a las costas de Coquimbo (Lacoste, 1997: p.579) y, al mismo tiempo, se agudizaba el problema con el Gobierno uruguayo por la cuestión de las presas.

En medio de esta conflictiva trama, para el columnista del periódico chileno resultó lógico que La Nación Arjentina, en tanto "órgano semi-oficial del gobierno"20, defendiera irracionalmente la entrada en la guerra y la firma del tratado con Uruguay y Brasil. Sin embargo,

18 El Mercurio, 24 de marzo de 1865, p.2.

19 El Mercurio, 14 de noviembre de 1865, p.2.

20 "Boletín del día", El Mercurio, 14 de noviembre de 1865, p.2. 
le pareció extraño que atento al sentido americanista que creían hallar en el presidente Mitre, el diario no fuera categórico en su condena a los ataques españoles. Por tal motivo, desde El Mercurio se advertía al público lector la preeminencia de intereses nacionales y la enemistad hacia Chile (imagen especialmente construida sobre el potencial afán expansionista de su Gobierno) como base del discurso del medio bonaerense, en una opinión que no representaba el sentir del pueblo argentino, el cual daba constantes señales de contrariedad frente a ambas guerras.

El desastre de Curupayty (22 de septiembre de 1866) también resultó ocasión propicia para encender el fuego cruzado dentro del espacio publicitario. A finales de octubre de 1866, la prensa chilena respondió a rumores referidos a la celebración de la derrota aliada en Santiago. Según el redactor, al contrario de las opiniones compartidas por los medios argentinos, desde Chile solo se expresaban "muestras de dolor por la hecatombe de la brillante oficialidad arjentina". No obstante, mantenían su firme oposición respecto a la continuidad de la guerra:

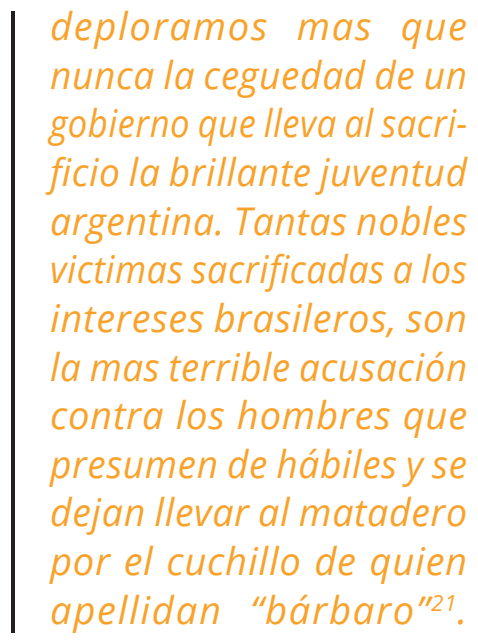

Por otra parte, El Mercurio en ocasiones obvió estas intervenciones directas y prefirió la transcripción de editoriales o noticias de otros periódicos locales. En especial, interesa mencionar la constante referencialidad respecto a El Independiente, el cual ejecutó una punzante crítica sobre la Guerra del Paraguay y el rol de los aliados en el conflicto. En primer

21 El Mercurio, 29 de octubre de 1866, p.2. Ver también algunas opiniones al respecto aparecidas en El Nacional y que migraron al soporte de Valparaíso: "Alegría insensata (El Nacional)", El Mercurio, 10 de diciembre de 1866, p. 2.; y El Mercurio, 12 de diciembre de 1866, p.2. 
término, destacan los ácidos comentarios de dicho medio ante la rúbrica del tratado de la Triple Alianza, al que definió como "anómalo" y "repugnante"22, en particular por el protagonismo que entregaba al Imperio del Brasil. Para el redactor del periódico, este documento era una clara muestra de que el Uruguay ya se encontraba bajo el yugo de Pedro II y solo era dable confiar en un cambio de política del Gobierno de Mitre como mecanismo para frenar las apetencias del Emperador.

Otro ejemplo de esta migración textual desde El Independiente aparece en un editorial de abril de 1865, donde los responsables de aquel diario cuestionaron los ataques del ejército comandado por Mitre con el objeto de una supuesta "cruzada libertadora" sobre el Paraguay. Pero no solamente criticaron el objeto que impelía la marcha de las fuerzas aliadas -la irrupción civilizatoria para liberar al pueblo del tirano López-, sino que también denunciaron que muchos paraguayos hacían causa común con este propósito y marchaban a la vanguardia del ejército invasor. Esta acusación fue acompañada por la condena de Joaquín Godoy, como redactor de El Mercurio, para quien “jamás la posteridad [los] coronará como héroes", pues "se alían con el enemigo estranjero para llevar la guerra a su propia patria"23.

Asimismo, otra destacada incursión de aquel periódico se observa en octubre de 1866, tras el arribo de las noticias sobre la batalla de Curuzú (3 de septiembre de 1866), cuando una de sus editoriales fue transcrita por los colegas de Valparaíso. Según la nota, el triunfalismo que se expresó en los medios de la capital argentina no comprendía aún la gravedad del conflicto, los enormes costos que implicaba su continuidad (en recursos humanos y materiales) y el peligro que rodeaba al avance brasileño, que no solo comprometía las pretensiones del ejército aliado, sino que también ponía en peligro a las restantes repúblicas americanas. El redactor sostenía que se trataba de un conflicto que ya no contaba con el apoyo popular en Argentina -si es que alguna vez lo había

22 El Mercurio, 6 de junio de 1865, p.2.

23 El Mercurio, 17 de abril de 1865, p.3. 
tenido-, no sin dejar de advertir que "entre Curupaití y Humaitá [febrero de 1868] hai todavía bastante espacio para nuevas carnicerías". Asimismo, el texto responsabilizó a Mitre por su insistente estrategia en el avance sobre territorio paraguayo materializado en el desastre de Curupayty- y en cierta debilidad que mostraba respecto al Imperio y sus ambiciones ${ }^{24}$.

Esta migración textual hacia El Mercurio fue continua hasta 1870. Incluso en los estertores de la guerra, el periódico porteño fue un activo testigo de la polémica de aquel diario con La Tribuna de Buenos Aires. El centro del diferendo se hallaba en ciertas acusaciones lanzadas desde El Independiente relativas al carácter bárbaro de la avanzada aliada sobre el Paraguay y los abusos cometidos por sus ejércitos. El Mercurio publicó estas palabras, así como la respuesta que desde la redacción del medio bonaerense esgrimió el reconocido intelectual Santiago Estrada. En dicha intervención, Estrada respaldó la labor de las fuerzas argentinas en el Paraguay, las cuales no se orientaban a atacar al pueblo, sino a alejar a López del ejercicio del gobierno. El alegato, expuesto en acalorados términos, sostenía que:

la República Arjentina se armó, arrojó al ladrón a balazos, lo persiguió en to das sus guaridas, y lo ha de perseguir hasta que salga el parricida del país que ha asesinado, o vaya hacer ejercicios gimnásticos en la horca, que es donde los tiranos deben mantener el equilibrio, para no caer en tierra y morir despedasados [sic] por la muchedumbre 25 .

Como contraparte, si bien La Nación Arjentina no formó causa común con el resto de la prensa de Buenos Aires, se sirvió de ciertas coincidencias en la opinión sobre Chile y la prensa de aquel país para reafirmar su discurso. Diversas columnas de El Nacional y La Tribuna fueron utilizadas por Gutiérrez para atacar a los medios de comunicación trasandina por sus manifestaciones acerca de la política interna del país vecino y

\footnotetext{
24 El Mercurio, 5 de octubre de 1866, p.2.

25 El Mercurio, 6 de abril de 1870, p.2.
} 
el apoyo a despóticos gobiernos como el de López en Paraguay o Mariano Prado en el Perú. Por ejemplo, una columna de El Nacional de febrero de 1866, aparecida también en La Nación, señalaba lo inadecuado de las expresiones de los diarios chilenos, los cuales habían perdido el "buen juicio, el sentimiento de la justicia, ya que el de la gratitud hacia nosotros ha sido largo tiempo hace arrojado al agua, por ser el fardo mui pesado"26.

En el ámbito de la política regional también se observan elementos que tensaron la relación entre los medios de prensa chilenos y argentinos. Por una parte, la protesta del canciller peruano Toribio Pacheco -con el apoyo de Chile y Bolivia (Aljovín de Losada, 2009)- contra el tratado y los objetivos y rumbo de los acontecimientos de la guerra, generó una airada censura de La Nación Arjentina. El periódico bonaerense, atento a la comunidad de intereses entre Chile y Perú, acusó al primero de inducir al Gobierno de Lima para apoyar esta declaración. Tras bambalinas se creía en la presencia del ministro Covarrubias y en la proyección de un afán expansionista chileno sobre las costas del Atlántico. Unido a esta idea, también a las autoridades en Santiago se imputó el apoyo a Bolivia para un posible avance militar sobre territorio argentino y la instigación -con hombres, armas y dinero- a los revolucionarios de Mendoza, San Luis y San Juan frente al Gobierno de Buenos Aires ${ }^{27}$.

\section{La defensa de un pueblo que resiste}

\section{"En Chile son paraguayos porque no hemos ido a derramar por ellos nuestra sangre", es el resu- men de todas las filípicas de la prensa argen- tina. El Mercurio, 12 de diciembre de 1866, p.2.}

26 "La prensa chilena (El Nacional)", El Mercurio, 19 de febrero de 1866, p.2.

27 El Mercurio, 25 de septiembre de 1866, p.3; "Revista de la Quincena", El Mercurio, 3 de diciembre de 1866, p.2; El Mercurio, 10 de diciembre de 1866, p.2; y “Actualidad arjentina”, El Mercurio, 21 de marzo de 1867, p.2. 
En abril de 1865, el intelectual chileno Benjamín Vicuña Mackenna advirtió a Mitre que buena parte de la prensa local había fijado posición en favor de la causa paraguaya. Según su parecer, la escasa y deficiente información que llegaba desde Buenos Aires sobre las causas y las implicaciones de cada gobierno en su desarrollo, hacía de esta una acción más movida "por [el] instinto que por [el] convencimiento". Asimismo, aclaró que, en el caso de El Mercurio, el periódico de la ciudad portuaria no respondía en su posición "a un sistema de política fijo", por lo que sus opiniones al respecto solo estaban influidas por el interés de sus editores ${ }^{28}$.

En tal sentido, y aunque con algunos matices, la línea editorial del periódico accionó una acérrima defensa a la causa paraguaya, en la medida en que no solo patrocinó la integridad americana y condenó una guerra fratricida, sino también porque sirvió, de manera subyacente y adyacente, para atacar a aquellos que habían negado el apoyo a las demandas chilenas en el conflicto del Pacífico. La hostili- dad uruguaya y la pasividad del Gobierno argentino apuntalaron un discurso que, aunque evitaba los ataques directos a ambos estados, marcó una irreductible posición de admiración hacia los enemigos de la Triple Alianza.

Como contraparte, uno de los pilares que articuló la visión del periódico guarda relación con el peligro imperial. En este caso, fue también el propio Florentino González quien inauguró una intensa campaña en las páginas del impreso para advertir sobre las desmedidas apetencias del Gabinete de Río de Janeiro. Tal preocupación no era circunstancial, sino que ya había sido expuesta por el diplomático e intelectual colombiano desde inicios de la década en distintas intervenciones dentro del espacio publicitario local. De tal suerte, dos artículos publicados en la Revista del Pacífico en 1861 ("Límites de las naciones hispano-americanas" y "Las repúblicas hispanoamericanas y el principio del uti posidetis") advertían sobre los artilugios utilizados por la política brasileña para ganar terreno en el continente mediante la acción

28 Carta de Benjamín Vicuña Mackenna a Bartolomé Mitre. Santiago, 2 de abril de 1865 (Archivo del General Mitre, 1912: p.47). 
diplomática o la ocupación militar y, de ese modo, imponerse sobre las diversas repúblicas. A esta preocupación se sumó, luego del estallido la guerra en el Pacífico, el miedo ante una posible alianza entre Brasil y España para tomar el control del continente sudamericano y poner en peligro lo conquistado tras la independencia.

Así, desde finales de 1864, la redacción del periódico comenzó a construir esta imagen expansionista alrededor de dos eventos: el incidente entre el vapor paraguayo Tacuarí y el paquete brasileño Marqués de Olinda (12 de noviembre de 1864) y el sitio de la ciudad de Paysandú (diciembre de 1864 - enero de 1865). En la selección de noticias y los comentarios que las acompañaron, resaltaron la unilateralidad del ataque brasileño y su interés excesivo por anexar sucesivamente los territorios uruguayo y paraguayo y con ello alcanzar el objetivo histórico de controlar la margen oriental del Plata y obtener la entrada marítima al sur del continente americano ${ }^{29}$.

Poco después, la movilización de las fuerzas de Solano López hacia el Uruguay para defender a su Gobierno del avance de las fuerzas imperiales presentó un nuevo escenario a González para exteriorizar su visión crítica sobre la acción del Brasil en el contexto regional. Aunque González advertía que al igual que el resto de la prensa chilena no estaba interesado en tomar partido en un conflicto interno como el que vivía el Uruguay, si se hallaba obligado a opinar de él en cuanto implicaba ciertos aspectos de política exterior con un alcance transnacional ${ }^{30}$.

A partir de ese momento, comenzó a elaborarse desde las páginas del soporte un discurso que hizo hincapié en la disparidad de fuerzas entre los contendientes y que confundió sus opiniones favorables sobre

29 El Mercurio, 23 de diciembre de 1864, p.3 y “Crónica estranjera. El asalto de Paysandú", El Mercurio, 10 de enero de 1865, p.2. La caída de Paysandú fue varias veces comparada, a partir de 1866, con el bombardeo de Valparaíso, en tanto hitos en los que fue atacada la legalidad en pro de intereses antiamericanos. El Mercurio, 27 de diciembre de 1866, p.2.

30 El Mercurio, 24 de marzo de 1865, p.2. 
el pueblo y el Gobierno del Paraguay. Respecto al primero, El Mercurio destacó en numerosas editoriales el valor de la lucha del pueblo paraguayo, resaltado especialmente alrededor de tres eventos: la firma del tratado de alianza; el desastre de Curupayty -como ya se vio en el intercambio con La Nación Arjentina-y la resistencia final de los habitantes frente a la presión de las fuerzas coaligadas.

En torno a la firma del tratado, el periódico chileno se valió de la propia prensa argentina opositora para presentar sus opiniones acerca del documento. De tal forma, compartió con sus lectores diversas editoriales de la Reforma Pacífica y La América que objetaban la alianza con el Brasil, el avance de sus ejércitos y la lucha contra un pueblo inocente. La construcción de la imagen paraguaya como una alteridad bárbara que era necesario someter y civilizar para sacarla de sus errores y entregarle la libertad fue rechazada por El Mercurio. Asimismo, insistió en la idea de una guerra inútil que implicaba a naciones hermanas y donde la diplomacia no había agotado todos los canales existentes para detener un enfrentamiento armado. Incluso, a este respecto, el diario de Valparaíso afirmó que encontraba a Solano López dispuesto a negociar y firmar una paz con Argentina, pero jamás a pactar con el Brasil.

Esta intransigencia del mandatario paraguayo respecto de la presión imperial fue celebrada por la prensa trasandina, en vistas de la amenaza antirrepublicana que representaba para el resto de los países del continente. En tal sentido, El Mercurio expresaba que los Gobiernos de Uruguay y Argentina habían desestimado este peligro y firmado este tratado que exponía a todo el continente a un futuro avance y ocupación de las armas de Pedro II. A partir de ello, la crónica del periódico afirmaba:

No, no tenemos aplausos para estos pretendidos Metternich del Plata, que han comprometido a su patria en una guerra que no encuentra simpatías ni en Europa ni en América. Harán del Paraguai o un vencedor orgulloso, o un martir de su independencia. Vencido el Paraguai, siempre caería 
envuelto en un sudario glorioso empapado con sangre arjentina ${ }^{31}$.

A modo de vaticinio, las editoriales que se sucedieron apelaron a resaltar el carácter heroico de la resistencia del pueblo frente a los embates del enemigo aliado. Incluso, para generar mayor empatía entre los hechos y los lectores del periódico, en agosto de 1868 se publicó una carta de un chileno -cuya identidad se desconoce- que habría desembarcado en Curupayty con el fin de recorrer el teatro de la guerra y transmitir de cerca la "formidable defensa que tenían los paraguayos"32. En tal sentido, el aumento del género epistolar como mecanismo para reflejar los acontecimientos de la guerra fue evidente hacia el final del conflicto. En estas piezas, casi siempre enviadas desde Buenos Aires o Asunción, se apelaba a las imágenes desgarradoras de la lucha de niños y mujeres frente al invasor, instantáneas de un pueblo que prefería morir bajo fuego enemigo que entregar las armas y rendirse ${ }^{33}$.

Asimismo, las crónicas y editoriales que acompañaron estas misivas intentaron resaltar la figura de Francisco Solano López como gran líder popular de la resistencia, siempre en aras de alimentar la posibilidad de una potencial victoria paraguaya en el conflicto. Según El Mercurio, López había aprovechado las ventajas que le daba el conocimiento del terreno y el ascendiente que tenía sobre el pueblo para mantener latente la esperanza de "una raza bravía, que sabe que lo que defiende es su propia independencia y la seguridad de su territorio [... $]^{\prime \prime 34}$.

Esta defensa de López y su pueblo también accionó constantes y duros ataques de la opinión pública argentina hacia Chile, práctica que el periódico porteño bautizó como "chilo-ma-

31 El Mercurio, 29 de octubre de 1866, p.2.

32 La carta, fechada en Buenos Aires el 11 de julio de 1868, llevaba el título de "Paraguai. Una visita al teatro de la guerra por un chileno", El Mercurio, 23 de agosto de 1868, p.2. Ver también El Mercurio, 15 de agosto de 1868, p.2.

33 El Mercurio, 15 de octubre de 1869, p.2 y El Mercurio, 12 de febrero de 1870, p.2.

34 El Mercurio, 5 de octubre de 1866, p.2. 
nía"35. La disputa discursiva a nivel periodístico generó tensión a ambos lados de la Cordillera y puso en el punto de mira no solo al diario de Valparaíso, sino también a los funcionarios chilenos en Buenos Aires, quienes denunciaron correr peligro frente a la escalada de violencia tras la toma de posición contraria a la triple alianza ${ }^{36}$.

\section{Reflexiones finales}

La batalla dialéctica para imponer una determinada versión sobre los sucesos y fijar posición dentro del ámbito de la opinión pública regional tuvo en El Mercurio un actor protagónico. El contenido de sus páginas manifestó una enorme resonancia gracias a su amplia circulación por los principales emporios editoriales de América y Europa. Igualmente, su locación en Valparaíso, en tanto canal de entrada para las noticias, le permitió estar actualizado respecto a los principales acontecimientos a nivel global y brindar a sus lectores las más destacadas novedades sobre los conflictos tanto dentro como fuera de fronteras.

En tal sentido, las noticias sobre la guerra del Paraguay llegaron a la redacción del periódico y fueron ganando,

poco a poco, mayor espacio dentro de los contenidos del soporte. Durante todo el enfrentamiento, la información que se canalizó mediante diversos formatos -transcripción de noticias, documentos, editorialesacaparó el interés lector y fue formando opinión sobre el conflicto y sus protagonistas.

Sin embargo, el periódico funcionó no solo como canal para irradiar las noticias, sino también como herramienta política con una clara postura, que alternó los ideales americanos con los intereses nacionales. De tal forma, en su construcción discursiva sobre el conflicto paraguayo se superpusieron juicios y comentarios sobre la guerra que en las márgenes del Pacífico enfrentaba a España con Chile y otras naciones americanas, así como la ten-

\footnotetext{
35 El Mercurio, 10 de abril de 1867, p.2.

36 El Mercurio, 21 de marzo de 1867, p.2.
} 
sión subyacente alrededor de la disputa limítrofe en la Patagonia.

Desde ese punto de partida, el recorrido a través de las páginas del periódico porteño descubrió, en primer término, el continuo reproche respecto a la acción diplomática del Gobierno chileno en el espacio rioplatense. José Victorino Lastarria solo fue el "chivo expiatorio" de una crítica más amplia, orientada a evidenciar la debilidad de la estrategia del presidente Pérez para ganar territorio hacia el Atlántico y obtener los apoyos necesarios para vencer a los españoles.

De igual forma, la exégesis documental reveló las complejas formas de construcción del discurso político en los espacios de la prensa; las tensiones, los diálogos y las inversiones de alianzas que se procesaron tanto a nivel local como internacional. La oposición entre El Mercurio y La Nación Arjentina fue testimonio de esas fricciones al interior del campo publicitario regional; disputa en la que también se solaparon los intereses nacionales y la proyectada unidad americana.
Por último, se reflejó en las líneas editoriales del formato una apoyo cada vez más irrestricto a la causa paraguaya, y una defensa de su pueblo y su Gobierno. A partir de un discurso que resaltó la lucha por la soberanía del Paraguay frente al afán expansionista brasileño -y la pasividad de Argentina y Uruguay- comenzó a ganar las simpatías del lector chileno. Incluso, algunas obras sobre la historia -actual y pasada- de aquel país comenzaron a circular en el mercado chileno y fueron comercializadas por las principales librerías de la ciudad. La Historia de la Guerra del Paraguay (1869) de Jorge Thompson (traducida al español por David Lewis y Ángel Estrada) o Los Comuneros del Paraguay (1865) de José Manuel Estrada llegaron al público del enclave portuario y su venta se intensificó, especialmente durante el año 1870, lo que da muestras de un mayor interés por conocer la realidad de aquel país, surgido a partir de las noticias sobre el enfrentamiento armado.

En suma, El Mercurio se posicionó dentro del mercado editorial y publicitario como un soporte comunicacional rele- 
vante, aproximando a partir miento-, al mismo tiempo que de diversas manifestaciones construyó una opinión particular textuales una realidad lejana sobre los acontecimientos que y desconocida para sus lectores ocurrían en el Paraguay deci-y los acicateó en su conoci- monónico durante la guerra. 


\section{Referencias bibliográficas}

Aljovín de Losada, C. 2009. “El Perú y la guerra del Paraguay, 1864-1870", Nuevo Mundo. Mundos Nuevos. En https://doi.org/10.4000/nuevomundo.48562 (Consultado 10 de abril de 2020).

Alonso, P. 2015. “La historia política y la historia de la prensa: los desafíos de un enlace", en Adriana Pineda Soto (coord.), Recorridos de la prensa moderna a la prensa actual, México, Universidad Autónoma de Querétaro, pp. 11-34.

Archivo del General Mitre, 1912. Correspondencia Literaria (Conclusión). Años 1859-1881, Tomo XXI, Buenos Aires, Biblioteca La Nación.

Arenas Deleón, N. 2019. “Sembrar en áridos campos. La Revista del Pacífico, la república letrada y la oposición al gobierno conservador de Manuel Montt (1858-1861)", Antíteses. Revista do Programa de Pós-Graduação em História Social da Universidade Estadual de Londrina, Vol. 12, No. 23, pp. 57-79.

Austin, J. 1962. Cómo hacer cosas con palabras, Barcelona, Paidós.

Baratta, V. 2012a. "La identidad nacional argentina durante la Guerra del Paraguay. Representaciones, lenguajes políticos y conceptos en el diario La Nación Argentina (1862-1870)", Almanack, No. 3, pp. 82-98.

Baratta, V. 2012b. “La oposición a la Guerra del Paraguay en Buenos Aires. Un análisis de las representaciones de la nación argentina en el periódico La América", Revista Electrónica da ANPHLAC, No. 13, pp. 83-108.

Caballero, H. y Ferreira, C. 2007. “El periodismo de guerra en el Paraguay (1864-1870)", en Nicolas Richard, Luc Capdevila y Capucine Boidin (eds.), Les guerres du Paraguay aux xixe et xxe siècles, París, CoLibris, pp. 487500 .

Collier, S. 2005. La construcción de una república, 1830-1865. Política e ideas, Santiago, Ediciones Universidad Católica de Chile.

Doratioto, F. y Monteoliva, F. 1993. "A imprensa de oposição e a política brasileira em relação ao Paraguai (1869-1875)", Textos de História, No. 1, pp. 77-102.

Gobierno de Chile, 1865. Censo Jeneral de la República de Chile, Santiago, Imprenta Nacional.

Ibarra Cifuentes, P. 2014. “Liberalismo y prensa: leyes de imprenta en Chile decimonónico (1812-1872)", Revista de Estudios Histórico-Jurídicos, No. 36, pp. 293-313.

Johansson, L. 2012a. “Conflicto bélico y prensa en Paraguay durante la guerra de la Triple Alianza (1864-1870)", Cuadernos de Marte, No. 3, pp. 
$187-222$

Johansson, L. 2011. “Inspiración bajo el estampido del cañón. Tensiones en torno a la escritura de la prensa en los periódicos de trinchera paraguayos (1867-1869)", Folia Histórica del Nordeste, No. 20, pp. 117-138.

Johansson, L. 2017. La gran máquina de publicidad. Redes transnacionales e intercambios periodísticos durante la guerra de la Triple Alianza (18641870), Sevilla, Universidad Internacional de Andalucía.

Johansson, L. 2012b. "Paraguay contra el monstruo anti-republicano. El discurso periodístico paraguayo durante la Guerra de la Triple Alianza (1867-1869)", Historia Crítica, No. 47, pp. 71-92.

Johansson, L. 2014. Soldados de papel. La propaganda en la prensa paraguaya durante la guerra de la Triple Alianza (1864-1870), Cádiz, Fundación Municipal de Cultura.

Johansson, L y Sujatovich, L. 2012. “Papeles de guerra. Causas de la Guerra de la Triple Alianza a través de la prensa argentina y paraguaya (18621870)", Revista Universum, Vol. 2, No. 27, pp. 99-111.

Johnson, A. 2006. "Cara feia al enemigo: The Paraguayan Press and The War of Triple Alliance", The Colorado Review of Hispanic Studies, Vol. 4, pp. 169-185.

Lacoste, P. 1995-1996. "Las guerras hispanoamericanas y de la triple alianza. La revolución de los colorados y su impacto en las relaciones entre Argentina y Chile", Historia, Vol. 29, pp. 125-158.

Lacoste, P. 1997. "Americanismo y guerra a través de El Mercurio de Valparaíso (1866-1868)", Estudios Americanos, Vol. 54, No. 2, pp. 567-591.

Lastarria, J.V. 1968. "Cartas enviadas por don José Victorino Lastarria durante su misión en el Río de la Plata, 1865-1866", Historia, No. 7, pp. 313-330.

Louis, A. 2014. "Las revistas literarias como objeto de estudio", en Hanno Ehrlicher y Nanette Rißler-Pipka (eds.), Almacenes de un tiempo en fuga: Revistas culturales en la modernidad hispánica, Aachen, Shaker Verlag, pp. 31-58. En https://www.revistas-culturales.de/es/buchseite/annick-louis-lasrevistas-literarias-como-objeto-de-estudio (Consultado 10 de enero de 2018)

Ossandón, C. 1998. El crepúsculo de los sabios y la irrupción de los publicistas, Santiago, LOM.

Paatz, A. 2001. "The Socio-Cultural Function of Media in Nineteenth-Century Latin America", CLCWeb Comparative Literature and Culture, Vol. 3, No. 2, pp. 1-9. 
Quesada, V. y Navarro Viola, M. 1866. "Bombardeo de Valparaíso. Protesta de la prensa de Buenos Aires", La Revista de Buenos Aires, Vol. 9, №34, pp. 274-276.

Román, C. 2016. Diseños transnacionales. La prensa satírica en la Guerra de la Triple Alianza (1865-1870)", Literatura y Lingüística, No. 34, pp. 131 150.

Rubilar, M. 2015. “La Prusia americana: prensa argentina e imaginario internacional de Chile durante la Guerra del Pacífico (1879-1881)", Revista de Historia y Geografía, No. 33, pp. 83-121.

Salazar, G. 2009. Mercaderes, empresarios y capitalistas (Chile, siglo XIX), Santiago, Sudamericana.

Santa Cruz, E. 1988. Análisis histórico del periodismo chileno, Santiago, Nuestra América.

Scavone Yegros, R. 2018. Paraguay y Colombia: Del reconocimiento a la segunda reelección de Stroessner (1846-1963), Asunción, Tiempo de Historia.

Silva Castro, R. 1958. Prensa y periodismo en Chile (1812-1956), Santiago, Ediciones de la Universidad de Chile.

Silveira, M. 2009. A batalha de papel. A charge como arma na guerra contra o Paraguai, Florianópolis, Editora UFSC.

Silveira, M. 2014. "Os múltiplos papéis do jornalismo brasileiro na Guerra contra Paraguai", História, Vol. 5, No. 1, pp. 213-236.

Subercaseaux, B. 2000. Historia del libro en Chile (Alma y cuerpo), $2^{\text {a }}$ edición, Santiago, LOM.

Sujatovich, L. 2014. “La Nación Argentina (1862-1869): su posicionamiento editorial respecto a la conformación del Estado nacional y a la guerra de la Triple Alianza", Tesis de Doctorado en Comunicación, La Plata, Universidad Nacional de la Plata.

Tornero, S. 1889. Reminiscencias de un viejo editor, Valparaíso, Imprenta de la Librería del Mercurio.

Valero, P. 2015. “Un imperio entre un mar de repúblicas: Brasil frente a las repúblicas del Plata (1865-1870)", Tesis de Maestría en Estudios Latinoamericanos, México, Universidad Autónoma de México.

Whigham, T. 2012. "Building the Nation While Destroying the Land: Paraguayan Journalism during the Triple Alliance War, 1864-1870", Anuario de Historia de América Latina, No. 49, pp. 157-180. 